\title{
A “gramática saudável” de Kant
}

\author{
Pedro Pimenta \\ Professor do Departamento de Filosofia da \\ Universidade de São Paulo (USP)
}

Resumo: Trata-se de ler uma passagem recorrente nos cursos de lógica de Kant para examinar as razões para que o filósofo tenha insistido na comparação entre lógica e gramática a propósito do tópico da espontaneidade da razão. Sugerimos que a discussão desse tópico está estreitamente vinculada à definição do que se entende na Crítica por "filosofia como sistema".

Palavras-chave: Lógica, Gramática, Transcendental, Razão, Espontaneidade

\begin{abstract}
The paper discusses the famous comparison made by Kant in his courses on logic between logic and grammar so as to show that the recurrence of this topic is central to Kant's discussion of the relationship between spontaneity of reason and philosophy as a system.
\end{abstract}

Keywords: Logic, Grammar, Transcendental, Reason, Spontaneity.

.en voulant faire mieux que la nature vous faites plus mal; vos oreilles et votre goût son gâtés par un art mal entendu. Rousseau, Ensaio sobre a origem das linguas. ${ }^{1}$

1. Rousseau, J.J. Essai sur l'origine des langues, “cap. IV”. Paris: Gallimard, 1990, p. 123. 
Para introduzir seus estudantes no "conceito da lógica", o professor Kant não costumava seguir a mesma ordem expositiva da Lógica transcendental na Crítica da razão pura. Preferia introduzir o assunto recorrendo a uma comparação ou analogia entre poderes da natureza e poderes do homem. No mais antigo registro de seus cursos de lógica, feito por Herder em 1762, encontramos a primeira versão dessa comparação:

Tudo acontece segundo regras. Uma pedra [cai], a água flui, como o homem em suas atividades mecânicas. - As atividades do entendimento são a consciência de fenômenos na natureza. - Os homens seguem essas regras inconscientemente, por mero hábito, sem consciência, e é apenas com o exercício do entendimento, também freqüentemente sem regras, que se tornam conscientes delas, mediante a experiência. Mas nem tudo pode ser conhecido mediante a experiência: um uso mais elevado é exigido para movimentos como os da dança, por exemplo, que requerem de antemão um conhecimento versado em regras. A lógica ou logos, como ratio instrumentum, é como que o modelo das regras lógicas. ${ }^{2}$

A primeira frase - de forte teor leibniziano - reaparecerá, com algumas variações, na abertura de todos os registros de exposições dos cursos de lógica ministrados por Kant, até a década de 1790, como uma espécie de bordão ou de fórmula encantatória para iniciar os estudantes no mundo da lógica. $\mathrm{O}$ intuito da comparação entre o movimento na natureza e o movimento no homem é mostrar que são regidos pelos mesmos princípios mecânicos, com a diferença de que no homem a inconsciência desses princípios é o estado de uma consciência latente deles, que pode se efetivar ou pelo exercício do entendimento ou pela instrução. E se compararmos uma das frases centrais da passagem anotada por Herder em 1762 - "As atividades do entendimento são a consciência de fenômenos na natureza". - com esta anotação de 1789, feita por Pölitz - "entendimento significa a faculdade de trazer sob

2. Kant, I. Vorlesungen über Logik ("Lógica Herder"). In:__. Kants Schriften, 24.1, 2 vols. Berlim: Walter de Gruyter, 1966, p. 03. Sobre a datação das lições de lógica, cf. o esclarecimento de Lehmann, 24.2, pp. 976ss. 
regras as representaçôes do sentido" - veremos que esta última é uma definição "filosófico-dogmática", que explica o que é o entendimento a partir do princípio que rege a sua atividade, enquanto a frase de 1762 é puramente "histórico-descritiva", mostra o que o entendimento faz sem explicar o por quê desse fazer. ${ }^{4} \mathrm{O}$ teor quase casual de 1762 dá lugar em 1789 a uma formulação gramatical. Diante dessa transformação, que em certo sentido é um aprimoramento, não admira que a comparação realizada por Kant se desenvolva, em registros posteriores, apresentando um paralelo entre a lógica como ciência do pensamento e a gramática como ciência da linguagem. No manual de lógica, publicado em 1800, encontra-se a seguinte observação:

Tudo na natureza, tanto no mundo animado quanto no mundo inanimado, acontece segundo regras, muito embora nem sempre conheçamos essas regras. A água cai segundo leis da gravidade e, entre os animais, a locomoção também ocorre segundo regras. $\mathrm{O}$ peixe na água, o pássaro no ar movem-se segundo regras. A natureza inteira em geral nada mais é, na verdade, do que uma conexão de fenômenos segundo regras; e em nenhuma parte há irregularidade alguma. Se pensamos encontrar tal coisa, só poderemos dizer neste caso o seguinte: que as regras nos são desconhecidas. $\mathrm{O}$ exercício de nossos poderes também acontece segundo certas regras que seguimos, a princípio, sem consciência delas, até chegarmos aos poucos ao conhecimento delas mediante diversas tentativas e um prolongado uso de nossos poderes, tornando-as por fim tão familiares que muito esforço nos custa pensá-las in abstracto. Assim, por exemplo, a gramática geral é a forma de uma língua em geral. Mas também falamos sem conhecer a gramática; e quem fala sem conhecê-la tem realmente uma gramática e fala segundo regras das quais, porém, não está consciente. ${ }^{5}$

3. Kant, I. Vorlesungen über Logik ("Lógica Pölitz"). In: 24.2, p. 502

4. Kant, I. Lógica Jäsche. Introdução, seção III. Trad. Guido de Almeida. Rio de Janeiro: Tempo Brasileiro, 1992. A mesma distinção entre essas espécies de conhecimento ocorre em todos os cursos posteriores ao registrado por Herder em 1762.

5. Kant, I. Lógica Jäsche, A 01-2. 
Apesar do que os distingue, há algo comum entre os poderes da natureza e os do homem (definido aqui como ser de razão): trata-se da espontaneidade com que são exercidos e se efetivam a partir de princípios que não precisam ser conhecidos ou sistematizados para serem utilizados. O pressuposto dessa consideração será explicitado na conclusão da Lógica transcendental: a experiência é pensada pela razão, em prol do entendimento, como uma totalidade sistemática, regida de acordo com leis a priori universalmente válidas, cujo princípio se encontra no entendimento como faculdade-de-julgar. Mas, assim como não é preciso refletir e chegar a essa constatação para pensar a natureza como sistema, tampouco é preciso ter lido a Crítica da razão pura para entender o que vai ser exposto ao longo deste curso de lógica; basta acompanhar o que é dito por Kant em sala de aula para reconhecer que é isso mesmo o que acontece, na natureza como no homem. O exemplo final é instrutivo: assim como os peixes nos rios e os pássaros no ar se movem segundo as leis da gravidade sem jamais as terem estudado, também os homens pensam sem terem sido instruídos na arte de pensar, e falam a língua do país em que foram criados sem terem aprendido a gramática dessa língua, e conhecem a forma da língua no mesmo ato em que se apoderam do seu conteúdo. A atividade precede a normatividade, e esta não é mais que a posterior sistematização de um conhecimento adquirido naturalmente. Tendo acompanhado Kant nessa rápida introdução, sua platéia está pronta para ser iniciada no conceito da lógica geral, ciência que expõe "as regras universais e necessárias do pensamento" e que, assim como a gramática geral, que "contém a mera forma da língua, sem as palavras", é "meramente uma ciência da forma de nosso conhecimento intelectual ou do pensamento" que abstrai de toda "matéria do mesmo". ${ }^{6}$

Se examinarmos agora passagens correspondentes a essa em registros anteriores dos cursos de lógica ministrados por Kant, encontraremos algumas variações interessantes.

6. Kant, I. Lógica Jäsche, A 04. 
$\mathrm{Na}$ lógica Blomberg (datada da década de 1770) se diz o seguinte:

A natureza como um todo atua de acordo com regras; assim, a água flui de acordo com regras hidráulicas, a natureza opera de acordo com regras, e mesmo o clima inconstante tem certas regras, embora não as percebamos. Os animais atuam de acordo com regras das quais não têm no mais das vezes a menor consciência. $\mathrm{O}$ homem age de acordo com regras e em particular faz uso do entendimento de acordo com certas proposições e regras. E quantas vezes não agem os homens de acordo com regras, sem terem consciência delas? Por exemplo, falam sua língua nativa. O emprego de nossos poderes muitas vezes ocorre sem termos consciência deles, e isso porque 1. Encontram-se em nossa própria natureza, 2. Graças à imitação, quando imitamos um exemplo para gradualmente adquirirmos o uso do entendimento tal como o vemos utilizado por outros; 3. Graças ao uso próprio, quando adquirimos na prática destreza no uso do entendimento sem a consciência de suas regras... O saudável entendimento comum cresce sem a instrução... As línguas já existiam antes dos gramáticos, os oradores antes da retórica, os poetas antes da poesia. ${ }^{7}$ afirma:

A lógica Dohna-Wundlacken (datada da década de 1780)

Deve-se refletir sobre o próprio pensamento, i.e., de acordo com regras. Toda língua se restringe a certas regras particulares. É esse o caso, sobretudo, das línguas mortas, a respeito das quais pode-se de fato designar-lhes as regras. Pode-se também fazer uso de regras sem lhes dar nomes. Aprendem-se essas regras gradualmente, por tentativas. As primeiras falham; posteriormente, adquire-se destreza. Entre as regras do pensamento, algumas são universais, aplicam-se indistintamente a objetos particulares. Também assim

7. Kant, I. Vorlesungen über Logik ("Lógica Blomberg"). In: Kants Schriften, 24.1, pp. 20-1. Consultamos, para a tradução das duas passagens seguintes, a tradução de J. M. Young: Lectures on Logic. Cambridge: University Press, 1992. A última frase de Kant é uma citação quase literal do verbete "Eloqüência", redigido por Voltaire em 1755 para a Encyclopédie, e citado também, na mesma época, por Condillac (Lógica, livro II, capítulo 03, $\S 02)$. 
há regras universais de linguagem. Uma tal gramática não contém palavras, não contém copia vocabularum, apenas a forma da linguagem. A doutrina universal do pensamento se chama lógica, doutrina do entendimento. É uma preparação para o pensamento de objetos... Regras lógicas não são aquelas de acordo com as quais pensamos, mas sim as de acordo com as quais deveríamos pensar. \{A lógica não contém absolutamente uma matéria, só a forma do pensamento\} A lógica deve conter princípios a priori. \{Portanto, a lógica é uma ciência e a gramática não, pois as regras desta são contingentes\}... É a lógica também um organon? Não, ela serve apenas à crítica, a exemplo da gramática (com a qual tem muita similaridade), a partir da qual não se aprende de fato uma língua, para o quê se requer um repertório de palavras. ${ }^{8}$

Das duas exposições, a última é a que mais se aproxima da Crítica da razão pura:

a lógica pode ser considerada numa dupla perspectiva: quer como lógica do uso geral, quer do uso particular do entendimento. A primeira contém as regras absolutamente necessárias do pensamento, sem as quais não pode haver nenhum uso do entendimento, e ocupa-se portanto deste, independentemente da diversidade dos objetos a que possa se dirigir. A lógica do uso particular do entendimento contém as regras para pensar corretamente sobre determinada espécie de objetos. À primeira pode-se chamar lógica elementar, à segunda órgão desta ou daquela ciência. ${ }^{9}$

$\mathrm{Na}$ Crítica da razão pura, a lógica geral é "a ciência das regras do entendimento" tomadas enquanto tais, desvinculadas de toda referência a objetos sensíveis e à experiência em geral. A lógica não é órgão do pensamento, é apenas seu cânon; e tal como a gramática não engendra línguas, a lógica não engendra o pensamento:

a lógica, verdadeiramente, deveria ser apenas o cânon para ajuizar do uso empírico do entendimento, e é abuso dar-lhe o valor de organon para uso geral e ilimitado, e constitui atrevimento julgar,

8. Kant, I. Vorlesungen über Logik ("Lógica Dohna-Wundlacken"). In: Kants Schriften, 24.2, pp. 694-5.

9. Kant, I. Crítica da Razão Pura. Trad. de Manuela Pinto dos Santos e Alexandre Fradique Morujão. Lisboa: Calouste-Gulbenkian, 1987, B 76. 
afirmar e decidir sinteticamente sobre objetos em geral, utilizando somente o entendimento puro. ${ }^{10}$

O “atrevimento" do lógico seria comparável ao do gramático que quisesse, pelo estudo da linguagem como estrutura, legislar sobre uma língua em particular ou sobre todas em geral sem considerar suas "regras contingentes".

Nas três exposições citadas - a de 1800, a da década de 70 e a da década de 80 -, a lógica geral, como ciência da forma do pensamento, é comparável à gramática geral como ciência da forma da linguagem. Essa comparação não é fortuita, sugere que haveria alguma relação entre essas ciências; e é de supor que tal relação seria decorrente de uma relação entre as atividades do espírito humano que elas sistematizam, o pensamento e a fala - sendo que esta última, por se realizar no órgão da voz, está mais próxima de uma ação espontânea da natureza do que o pensamento, que é exclusivamente humano. Seria a fala para Kant apenas um meio de transmitir pensamentos?

No opúsculo "Começo conjectural da história humana", Kant comenta duas passagens do gênese - "o homem deu nomes a todos os animais..." e "Esta sim é osso de meus ossos e carne de minha carne..." $(2,20 ; 23)$ - para mostrar que "exprimir-se é falar encadeando conceitos, logo é pensar" ${ }^{11}$ Essa tese é reiterada nas Lições de enciclopédia filosófica, onde se diz que "pensamos sempre em palavras" (wir doch in Worten denken). ${ }^{12}$ Essa afirmação da identidade entre pensamento e linguagem é o comentário de um tópico de Leibniz, que nos Novos ensaios corrigira a tese de Locke de que a finalidade principal da linguagem é comunicar pensa-

10. Kant, I. Crítica da Razão Pura, B 78.

11. Kant, I. "Começo conjectural da história humana". In: Kants Schriften, VIII, p. 110. Tradução francesa: __. Opuscules sur l'histoire. Trad. de Stéphane Piobetta. Paris: Flammarion, 1990, p. 147. Pode-se ler no original: “...ja reden, d.i. nach zusammenhängenden Begriffen sprechen, mithin denken”.

12. Kant, I. "Lições sobre enciclopédia filosófica". In: Kants Schriften, XXIX, p. 31; Ed. francesa: __. Abregée de philosophie ou Leçons sur l'Encyclopédie philosophique. Edição bilíngüe. Trad. Arnaud Pelletier. Paris: Vrin, 2009, pp. 106-7. 
mentos, acrescentando que "ela serve também para que cada um raciocine à parte consigo mesmo". ${ }^{13}$ Kant explora essa tese para mostrar que desde o momento em que o homem se põe a pensar, o pensamento se dá em linguagem, tem em vista a comunicação. ${ }^{14}$ Mas é preciso compreender o alcance dessa conclusão. Longe de retroceder à tese lockiana, ela aprofunda a reflexão leibniziana ao sugerir que é nesta última etapa de sua formulação - a comunicação verbal - que o pensar se torna coerente. Para que Adão possa dar nomes aos animais, é preciso que tenha o sentimento da diferenciação entre as respectivas representações deles; e para que ele possa dar nome à mulher, é preciso que tenha o sentimento da diferenciação dela em relação a si mesmo. Esse sentimento só se torna pensamento quando as representações são encadeadas a partir de signos lingüísticos. A linguagem, como "aptidão técnica" que o homem "adquire por si mesmo", serve para decompor e analisar o pensamento, ou para pensar; o fim último dessa exposição discursiva, que exprime e efetua para si mesmo, mas já com signos lingüísticos, é a apresentação sensível de conceitos com vistas à comunicação. ${ }^{15}$ Assim, o paralelismo entre forma do pensamento e forma da linguagem, mais que uma feliz coincidência, é a indicação inequívoca de que a coerência do pensar consigo mesmo poderá ser garantida e complementada pelo pensar para o outro e com o outro. ${ }^{16}$

Segundo a Antropologia de um ponto de vista pragmático, a consumação do pensamento na linguagem se dá pela utilização de caracteres verbais como "sinais meramente mediatos (indiretos) que em si nada significam, mas só por associação levam às intuições

13. Leibniz, W. G. Nouveax essays sur l'entendement humain, livro III, cap. 01, § 02. Ed. Brusnchwicg. Paris: Gallimard, 1994.

14. Cf. a respeito Capozzi, M. "Kant on logic and language". In: Buzzetti, D.; Ferriani, M. (orgs.). Speculative grammar, universal grammar, and philosophical analysis of language. Amsterdam: John Benjamins, 1997.

15. Kant,I. “Começo conjectural da história humana”.In:__. Kants Schriften, VIII, p. 110. Tradução francesa: Opuscules sur l'histoire, p. 147.

16. Kant, I. Kritik der Urteilskraft. Frankfurt am Main: Suhrkamp, 1974, § 40. 
e, por meio destas, a conceitos". ${ }^{17}$ Esse processo ocorre quando o homem se encontra "em estado de sociabilidade": assim como "em completa solidão ninguém adornará ou limpará sua casa", tampouco se sentirá incitado a dar uma "forma" a seus pensamentos para que se tornem compreensíveis, ou para que sejam dotados de "uma regra universal para o sentimento de prazer". ${ }^{18} \mathrm{~A}$ passagem de um estado a outro, da concepção de uma idéia de ordem à sua realização, é por intermédio de sinais indicativos, que significam intuições e conceitos que, tomados em si mesmos, se predispõem a uma tal conformação: "pensar é falar consigo mesmo (os índios de Otaheite chamam o pensar de linguagem do ventre) e, por conseguinte, também se ouvir interiormente (por meio da imaginação reprodutiva)". ${ }^{19}$ "Falar consigo mesmo" ainda não é como "falar suficientemente bem" ${ }^{20}$ mas para chegar a este estágio quase artístico no uso da linguagem, é preciso encontrar em si mesmo uma aptidão natural. Quando as crianças "perturbam" os adultos com seus gritos e sua agitação, essa expressividade, que não chega a ser linguagem, já contém, no entanto, os elementos necessários à comunicação. Há uma continuidade, uma transição natural prevista na natureza humana, do pensar silencioso ao pensar com signos verbais. ${ }^{21}$

Ora, se o homem pensa e fala antes de ter sido instruído na lógica ou na gramática, é forçoso reconhecer que essa instrução não só não acrescenta nada, quanto aos princípios, ao que a inteligência humana já possui, como tampouco propicia a aquisição de capacidades naturais ou inatas. Tudo o que podem a lógica e a gramática é incrementar ou refinar o uso de um talento que se encontra dado. Essas considerações são retomadas pela Crítica da razão pura. "O Juízo", diz Kant,

17. Kant, I. Antropologia de um ponto de vista pragmático. Trad. de Clélia Aparecida Martins. São Paulo: Iluminuras, 2006, § 38, p.89.

18. Kant, I. Antropologia de um ponto de vista pragmático, $\$ 67$.

19. Idem, $§ 39$.

20. Idem, $§ 01$.

21. Kant,I. “Começo conjectural da história humana”. In:___. Kants Schriften, VIII, p. 110. Tradução francesa: Opuscules sur l'bistoire, p. 147. 
é um talento que não pode ser ensinado, mas somente exercitado. A capacidade de julgar, por conseguinte, é também o cunho específico do assim chamado bom senso, cuja falta nenhuma escola pode remediar. Com efeito, se bem que a escola possa fornecer abundantemente e como que inocular num entendimento limitado regras tomadas de empréstimo a outros, ainda assim a capacidade de servir-se corretamente delas deve pertencer ao próprio aprendiz, e nenhuma regra que lhe possa ser prescrita para esse propósito estará segura de abuso quando lhe faltar um tal dote natural. ${ }^{22}$

$\mathrm{E}$, no entanto, do fato de que o juízo não possa ser ensinado não se segue que o seu princípio não possa ser examinado. Pelo contrário. É precisamente por ser fundada num talento natural que uma atividade deve ser estudada para ser compreendida do lado dos princípios que a tornam possível como efetividade. Daí a importância de uma lógica transcendental, ciência distinta da lógica geral que

indica, além da regra, ou melhor, da condição geral das regras que são dadas nos conceitos, também, simultaneamente e a priori, o caso em que a regra deve ser aplicada. [E isso porque] trata de conceitos que devem se referir a priori aos seus objetos, e cuja validade objetiva, por conseqüência, não pode ser demonstrada a posteriori, mas tem de poder expor, simultaneamente, segundo suas características gerais, mas suficientes, as condições pelas quais podem ser dados objetos de acordo com esses conceitos. ${ }^{23}$

Haveria, de modo similar, uma gramática trasncendental com "as condições gerais pelas quais podem ser dados objetos" de uma língua "de acordo com conceitos" de uma linguagem? Parece ser o caso, apesar da advertência da lógica Dohna-Wundlacken: "a lógica deve conter princípios a priori... portanto, a lógica é uma ciência e a gramática não", pois, como explica Márcio Suzuki ${ }^{24}$, a gramática "desempenha", na formação do pensamento crítico kantiano, "uma função heurística", e o próprio Kant menciona uma "gramática transcendental, que contém o fundamento da lin-

22. Kant, I. Crítica da razão pura, B 172.

23. Idem, B 175.

24. Suzuki, M. “A palavra como invenção. Heurística e linguagem em Kant”. In: Studia Kantiana, vol. 6/7 (2008), pp. 47-52. 
guagem humana", composta pelos princípios expostos na Estética e na Lógica transcendental - "a gramática é por certo uma doutrina do entendimento" (Grammatik ist freilich eines Verstandeslehre), e constitui, ao lado da lógica, o conjunto das regras que permitem trazer representações sob conceitos. ${ }^{25}$ Com esta diferença. Se a gramática não explica porque os fatos da língua são como tais $e$ não de outro modo, e permanece "uma mera disciplina" (nur eine Disciplin), mesmo da linguagem filosófica, a lógica transcendental explica porque as regras do pensamento são necessariamente essas e não outras, e é por isso uma "ciência; doutrina" (Wissensachaft, Doktrin). ${ }^{26}$

Uma obra como a Crítica da razão pura não é nem poderia ser produto da atividade puramente espontânea dos poderes intelectuais do homem. A filosofia é um conhecimento cuja forma é racional; é mais que uma compilação de registros e mais que um discurso espontâneo, é um discurso "erudito" (gelehrte), que se articula por escrito. ${ }^{27}$ Dissociando-se da palavra, tal como formada e emitida pelos órgãos da fala, esse discurso simplesmente ignora a dimensão sonora da linguagem, a ponto de a eufonia ser considerada uma "quimera"; como adverte Kant, a "congruência" de um escrito deve ser julgada unicamente pela "adequação do estilo à coisa" ${ }^{28}$ e nesse caso a linguagem é primordialmente um instrumento de construção de conceitos, a comunicação relegada a um papel secundário. Assim, embora as considerações sobre a espontaneidade do pensamento e da linguagem sugiram que uma boa parte do que se faz irrefletidamente, obedecendo-se de maneira cega aos poderes da natureza, é feito corretamente, a verdade é que nem tudo se alcança por essa via - a começar pela filosofia,

25. Kant, I. Vorlesungen über Logik ("Lógica Wiener"). In: Kants Schriften, 24.2, p. 790; cf. ainda, no mesmo volume, pp. 502-3 ("Lógica Pölitz").

26. Kant, I. Vorlesungen über Logik ("Lógica Busolt”). In: Kants Schriften, 24.2 , p. 609.

27. Kant, I. Vorlesungen über Logik ("Lógica Blomberg"). In: Kants Schriften, 24.2, p. 296.

28. Idem, p. 294. 
que consiste precisamente na reflexão sobre a condição de possibilidade de tudo o que é feito de acordo com a natureza.

Essa constatação, por óbvia que pareça aos leitores da Crítica da razão pura, coloca uma questão crucial, que pode ser formulada nos seguintes termos: faz melhor quem se atém ao fazer natural, ou quem procura aperfeiçoá-lo com a arte? A instrução deforma? Ou seria a arte capaz de melhorar a natureza? -, e vinha sendo discutida por filósofos, gramáticos e lógicos no Século das Luzes. ${ }^{29} \mathrm{~A}$ filosofia, a exemplo das outras ciências, embora realize uma disposição natural do homem, ${ }^{30}$ está longe de ser o produto de processos naturais deixados a si mesmos. A ciência, já dizia Kant em 1762, nasce na Grécia com "a liberdade, a emulação, o cuidado do corpo, a prosperidade", formas de organização e práticas sociais e individuais pelas quais o homem se distingue, por suas aptidões técnicas e com sua razão, dos demais membros do mundo natural. É então que a linguagem pode se tornar objeto de gramática. Tal ciência, se, por um lado, enriquece a compreensão do objeto ao oferecer dele um saber sistemático, gera, por outro lado, o equívoco de julgar o saber da língua pelo usuário espontâneo (o "erudito amador" - Gelehrte obne Profession) a partir dos critérios do estudioso da língua (o "erudito profissional" - Gelehrte von Profession), que nem sempre é dotado de uma sabedoria (Gelehrsamkeit) que o bom falante pode ter. ${ }^{31}$

A passagem das aulas de Kant em que se encontram essas considerações foi anotada por Herder, que parece ter feito um bom uso dela, anos mais tarde, no Ensaio sobre a origem da linguagem (1772). Explica-se ali que

uma vez que a gramática duma língua mais não é que uma filosofia sobre essa língua e um método para sua utilização, acontece neces-

29. Cf. Locke, Ensaio sobre o entendimento humano, livro IV, cap. 17, § 04 (4a edição, 1704); Harris, J. Hermes, or a philosophical inquiry concerning universal grammar, livro I, cap. 02 (1751); Ferguson, A. An essay on the history of civil society, parte III, seção 07 (1767).

30. Para o sentido preciso de "disposição natural" cf. Lebrun, G. "Une téléologie pour l'histoire ?". In: Kant sans kantisme, pp. 266-70. Paris : Fayard, 2009.

31. Kant, I. Vorlesungen über Logik (“Lógica Herder"). In: 24.1, pp. 04-6. . Kants Schriften, 
sariamente que, quanto mais próxima da origem está uma língua, menos gramática tem; e a língua mais antiga era apenas o atrás mencionado vocabulário da natureza. ${ }^{32}$

A constituição da gramática como sistema de uma língua é histórica, dá-se num processo conseqüente ao desenvolvimento de disposições naturais: "lentamente, a gramática ia-se formando. Assim, esta arte da fala, esta filosofia sobre a língua, só muito devagar e gradualmente se foi edificando, ao longo de séculos, de eras". ${ }^{33}$ Onde esse processo está mais adiantado, as línguas se tornam um meio para o progresso da razão que, por sua vez, ajuda no progresso do uso das línguas. ${ }^{34}$ Esse equilíbrio tem, no entanto, um custo. A arte da gramática substitui "a riqueza das determinações existentes no próprio léxico", suficientes para que a "linguagem viva", esse "simples confluir de imagens e impressões sem conexão nem determinação", resolvesse todos os problemas de análise e comunicação do pensamento. "Mas como pode alguma vez", pergunta-se Herder, "ter existido uma língua totalmente destituída de gramática? Um simples confluir de imagens e impressões sem conexão nem determinação? Tratava-se de linguagem viva, e isso resolvia ambos os problemas!". Resposta vaga, entretanto, que merece um esclarecimento: "a enorme adequação do gesto fornecia de algum modo a esfera e a medida a que pertencia esse confluir de imagens; e toda a riqueza das determinações existentes no próprio léxico substituía a arte da gramática”. É o que prova, segundo Herder,

a escrita dos povos do México. Essa gente representava simples imagens separadas. Quando não lhes ocorria uma imagem sensível, convencionavam certos riscos; a conexão entre eles tinha de ser dada pelo mundo a que pertencia cada um, adivinhada com base nele. E veja-se como hoje em dia os mudos e os surdos levam longe

32. Herder, J. G. Ensaio sobre a origem da linguagem, livro I, capítulo 03. Trad. de José M. Justo. Lisboa: Antígona, 1987, p. 106.

33. Idem, livro I, capítulo 03, p. 109.

34. Idem, livro I, capítulo 03, p. 111

35. Idem, livro I, capítulo 03, p. 109. 
esta arte divinatória que consiste em descobrir uma conexão a partir de sinais isolados...36

Herder afirma ainda que as "formas de economia" estrutural que se encontram nas primeiras línguas "tornar-se-ão tanto menos necessárias quanto mais for sendo introduzida no arranjo da língua uma gramática saudável" (gesunde Gammatik), que constituiria "uma filosofia da língua". ${ }^{37}$ Subjacente a essa concepção, encontrase, nas palavras de José M. Justo sobre esse texto, "a idéia de uma diversidade unificada pelos encadeamentos da discursividade", de uma "natureza permanente dentro da cadeia de progressão do gênero humano", e, portanto, de uma imbricação necessária entre as "forças" (Kräfte) naturais e sua expressão simbólica. Herder encontra na escrita a realização da mesma disposição que preside a expressão oral, sem ruptura entre natureza e arte. ${ }^{38}$

Se voltarmos agora a Kant, veremos que também para ele a diferença entre natureza e arte é mínima, quando se referem essas palavras ao homem. "A arte", diz a Crítica do Juizo, "distingue-se da natureza como o fazer se distingue do agir ou do atuar em geral, e o produto ou conseqüência da arte se distingue, enquanto obra, do produto da natureza como efeito." ${ }^{39}$ A dificuldade da arte é chegar a uma obra que, como produto do fazer técnico, tenha a mesma qualidade que o efeito da natureza como produto do agir espontâneo. Em todo caso, é preciso confiar que a disposição natural se basta, em certa medida, a si mesma, desde que não exceda um limite que, entretanto, é difícil de discernir. Cabe à arte encontrar esse ponto, em cada caso, aplicando uma técnica complementar à propensão natural. ${ }^{40}$

36. Idem, livro I, capítulo 03, pp. 109-10.

37. Idem, livro I, capítulo 03, p. 111.

38. Justo, J. M. "Posfácio". In: Herder, J. G. Também uma filosofia da história. Lisboa: Antígona, 1995, pp. 176-85.

39. Kant, I. Kritik der Urteilskraft, § 43, B 174. Cf. a mesma distinção em Kant, I. Vorlesungen über Logik ("Lógica Philippi"). In: 24.1, pp. 311-2.

40. Mesmo no caso da doença que atinge o corpo e ameaça a sua integridade e existência, Kant hesita em afirmar que a arte poderia efetivamente corrigir a natureza desviando- $a$ de sua tendência própria. Cf. a respeito Canguilhem, 
Isso vale tanto para as artes mecânicas quanto para as liberais. Nas ciências em geral, e na filosofia em particular, a dificuldade é fazer com que as "ciências sistemáticas" ou filosóficas (lógica, gramática) se mostrem convenientes ao estudo das "aptidões técnicas" naturais (pensar, falar) que são o seu objeto, sem submetê-los a regras arbitrárias em nome de um sistema. A Crítica da razão pura é um bom exemplo de que isso é possível. Se Kant pode afirmar que as duas partes que a compõem - Estética e Analítica transcendentais - contêm os elementos de uma gramática transcendental, é porque se ensina ali como "expressar um pensamento com exatidão" fazendo-se exatamente isso: expressando-se com exatidão, sem nada "ambíguo, vago ou equívoco", ${ }^{41}$ tornando-se disciplina do entendimento filosófico. Para chegar a esse grau de precisão, para escrever numa linguagem acertada, que embora seja fruto da mais alta reflexão parece perfeitamente conveniente ao assunto, Kant deve ter passado, na redação do texto, por um processo como o que Ricardo R. Terra chamou de "elaboração de esquemas sem coerção". ${ }^{42} \mathrm{O}$ esboço de pensamentos na linguagem realiza, por tentativa e erro, logo a posteriori, a esquematização, no texto de Kant, dos conceitos obtidos por reflexão, e permite assim ordená-los de acordo com as suas respectivas determinações lógicas. Ao expor o sistema completo dos princípios do conhecimento humano, a Crítica da razão pura delineia como que a "forma natural" do saber filosófico, ou a forma que ele deveria ter para fazer jus à tarefa que the cabe. Sem ensinar a pensar, ensina o leitor a ajustar seu pensamento à expressão mais rigorosa, e pode por isso, a justo título, ser considerada como uma possível "gramática saudável" da filosofia na época moderna.

\section{Bibliografia}

CANGUILHEM, G. "Thérapeutique, experimentation, responsabilité". In: _. Études d'histoire et de philosophie des sciences, 7a edição. Paris: Vrin, 2002.

G. "Thérapeutique, experimentation, responsabilité". In: Études d'histoire et de philosophie des sciences. 7a edição. Paris: Vrin, 2002, pp. 386-9.

41. Kant, I. Vorlesungen über Logik ("Lógica Blomberg"). In: Kants Schriften, 24.2, p. 295.

42. Terra, R. R. “Reflexão e sistema”. In:___. Passagens. Estudos sobre a filosofia de Kant. Rio de Janeiro: UFRJ, 2003, pp. 28-9. 
CAPOZZI, M. "Kant on logic and language". In: BUZZETTI, D.; FERRIANI, M. (orgs.). Speculative grammar, universal grammar, and philosophical analysis of language. Amsterdam: John Benjamins, 1997.

HERDER, J. G. Ensaio sobre a origem da linguagem. Trad. de José M. Justo. Lisboa: Antígona, 1987.

KANT, I. "Mutmasslicher Anfag der Menschengeschichte". In: Kants Scbriften, VIII. Berlim: Walter de Gruyter, 1966. . Vorlesungen über Logik. In: Kants Schriften, 24.1; 24.2. Berlim: Walter de Gruyter, 1966. . Kritik der Urteilskraft. Frankfurt am Main: Suhrkamp, 1974. Crítica da razão pura. Trad. de Manuela Pinto dos Santos e Alexandre Fradique Morujão. Lisboa: Calouste-Gulbenkian, 1987. "Conjecturs sur les débuts de l'histoire humaine". Trad. de Stéphane Piobetta. In: - Opuscules sur l'histoire. Paris: Flammarion, 1990.

. Lectures on Logic. Trad. de J. M. Young. Cambridge: University Press, 1992.

. Lógica. Trad. de Guido de Almeida. Rio de Janeiro: Tempo Brasileiro, 1992.

. Werke, vol. I. Herausg. G. Green. Frankfurt am Main: Deutscher Klassiker Verlag, 1993.

. Antropologia de um ponto de vista pragmático. Trad. de Clélia Aparecida Martins. São Paulo: Iluminuras, 2006.

. Abregée de philosophie ou Leçons sur l'Encyclopédie philosophique. Edição bilíngüe. Trad. Arnaud Pelletier. Paris: Vrin, 2009.

JUSTO, J. M. "Posfácio". In: HERDER. J. G. Também uma filosofia da bistória. Lisboa: Antígona, 1995.

LEBRUN, G. "Une téléologie pour l'histoire ?". In : Kant sans kantisme. Paris : Fayard, 2009.

LEIBNIZ, G. W. Nouveax essays sur l'entendement humain. Ed. Brusnchwicg. Paris: Gallimard, 1994.

ROUSSEAU, J. J. Essai sur l'origine des langues. Paris: Gallimard, 1990.

SUZUKI, M. "A palavra como invenção. Heurística e linguagem em Kant”. In: Studia Kantiana, vol. 6/7 (2008).

TERRA, R. R. "Reflexão e sistema”. In: filosofia de Kant. Rio de Janeiro: UFRJ, 2003. 